\title{
Vozes de aprendizes acerca de identidades sociais de raça/etnia na escola: percepção sobre materiais didáticos
}

\author{
Susana Aparecida Ferreira \\ Unioeste - Doutoranda \\ s.aferreira@hotmail.com \\ Aparecida de Jesus Ferreira \\ UEPG/Unioeste \\ aparecidadejesusferreira@gmail.com
}

\section{Resumo}

Este trabalho tem como objetivo refletir a respeito de algumas questões que cercam as identidades sociais de raça/etnia nos materiais didáticos (ou materiais de ensino) de alunos de duas salas de $8^{\text {a }}$ séries em duas escolas da cidade de Cascavel, no Estado do Paraná. Aqui as reflexões concentrar-se-ão em algumas entrevistas dos alunos das referidas escolas. O referencial teórico utilizado para dar suporte a esta pesquisa são: Schwarcz (1998), Moita Lopes (2002), Gomes (2003), Ferreira (2006; 2009), Azevedo (2009), Oliveira (2009), dentre outros. A natureza desta pesquisa é de cunho qualitativo e a metodologia, de base etnográfica, com entrevistas de alunos selecionados com base em questionários. Para as análises foram utilizados apenas excertos das entrevistas. As análises revelaram as percepções desses alunos acerca dos materiais de ensino e a relação deles com a raça/etnia na vida escolar e em sociedade. A pesquisa também demonstrou que as percepções dos alunos envolvem questões que muitas vezes podem estar naturalizadas por eles, e dessa maneira nem sempre lhes sendo perceptíveis.

Palavras-chave: Raça/etnia. Identidades sociais. Materiais didáticos.

\section{Abstract}

This work aims to reflect on some issues surrounding the social identities of race/ethnicity in didactic materials (or teaching materials) of male and female students in two 8th grade classes in two schools in the city of Cascavel, Paraná. These reflections focus on interviews with students at the aforementioned schools. The theoretical framework used to support this Horizontes de Linguística Aplicada, ano 12, n. 1, 2013 
research is: Schwarcz (1998), Moita Lopes (2002), Gomes (2003), Ferreira (2006), (2009), Azevedo (2009) and Oliveira (2009), among others. The nature of this research is qualitative and the methodology employed has ethnographic basis, with interviews with students selected by means of questionnaires. Only excerpts of the interviews were used for analysis. The analysis revealed the students' perceptions about the teaching materials and their relationship to race/ethnicity in school life and in society. The research also showed that the perceptions of male and female students often involve issues that may be naturalized by them, thus being not always perceived by them.

Keywords: Race/ethnicity, Social identities, Didactic material.

\section{Introdução}

O processo de construção das identidades sociais pode acontecer em todos os contextos e em todas as instituições sociais e, particularmente, no contexto escolar, foco deste trabalho. O objetivo é refletir acerca dos estudos sobre as percepções identitárias de raça/etnia a fim de contribuir para uma possível minimização da exclusão de alunos pertencentes à raça/etnia inferiorizadas socialmente e/ou nas salas de aula, por meio de reflexões sobre esses conceitos na construção identitária dos alunos. Esta pesquisa é um recorte de uma reflexão realizada com base em entrevistas com alunos de duas escolas públicas da cidade de Cascavel, no Estado do Paraná.

Primeiramente abordaremos o tema identidades sociais de raça/etnia; em segundo lugar, o tema raça/etnia e as relações com os materiais de ensino. Em terceiro lugar, discorreremos sobre a metodologia utilizada apresentando os alunos colaboradores. Em quarto lugar, apresentaremos a análise e a discussão dos dados com base nos excertos das entrevistas realizadas com esses alunos, seguidas das considerações finais.

\section{Identidades sociais de raça/etnia}

As identidades sociais não são fixas, estão sempre se construindo e se reconstruindo nos entrecruzamentos discursivos. Elas 
são plurais e configuram um verdadeiro caleidoscópio, são fragmentadas, e a respeito deste assunto Hall (2006, p. 75) postula:

Quanto mais a vida social se torna mediada pelo mercado global de estilos, lugares e imagens da mídia e pelos sistemas de comunicação globalmente interligados, mais as identidades se tornam desvinculadas - desalojadas - de tempos, lugares, histórias e tradições específicos e parecem "flutuar livremente". Somos confrontados por uma gama de identidades (cada qual nos fazendo apelos a diferentes partes de nós), dentre as quais parece possivel fazer uma escolha.

Moita Lopes (2002, p. 38) relaciona identidades sociais e contexto educacional afirmando que "as identidades sociais construídas na escola podem desempenhar um papel importante na vida dos indivíduos quando se deparam com outras práticas discursivas nas quais suas identidades são re-experienciadas ou reposicionadas", em um processo intersubjetivo, dialógico e relacional, e os efeitos de sentido criados estão sempre sujeitos ao olhar do outro (FABRÍCIO; MOITA LOPES, 2002, p. 6). Ainda a respeito das identidades sociais, Moita Lopes argumenta:

$E$ É portanto, a presença do outro com o qual estamos engajados no discurso (tanto no oral quanto no modo escrito) que, em última análise, molda o que dizemos, e, portanto, como nos percebemos à luz do que o outro significa para nós: "o indivíduo torna-se consciente de si mesmo no processo de tornar-se consciente do outros" (MARKOVA, 1990, p. 3 apud MOITA LOPES, 2002, p. 32).

As identidades são conhecidas por meio da alteridade, em confronto com o outro, com o diferente, e, pensando dessa forma, entendemos o quão importante é o trabalho com as identidades sociais de raça/etnia em sala de aula para que o aluno seja capaz de se reconhecer no seu material a respeito de sua raça/etnia.

Antes de iniciar a discussão sobre as identidades sociais de raça/etnia, trazemos os conceitos de raça, etnia, racismo, discriminação e estereótipo, tentando assim clarificar esses termos utilizados ao longo

Horizontes de Linguística Aplicada, ano 12, n. 1, 2013 
deste trabalho. Raça deve ser entendida no sentido construído social e historicamente na nossa sociedade (FERREIRA, 2006, p. 29). Segundo Gomes,

\begin{abstract}
[...] podemos compreender que as raças são, na realidade, construções sociais, políticas e culturais nas relações sociais e de poder ao longo do processo histórico. Não significam, de forma alguma, um dado da natureza. É no contexto da cultura que nós aprendemos a enxergar as raças (GOMES, 2005, p. 49).
\end{abstract}

Por sua vez, etnia é o outro termo usado para "se referir ao pertencimento ancestral e étnico/racial dos negros e outros grupos em nossa sociedade" (GOMES, 2005, p. 50), ou, ainda, “[...] uma etnia é um conjunto de indivíduos que, histórica ou mitologicamente, tem um ancestral comum; tem uma língua em comum, uma mesma religião ou cosmovisão; uma mesma cultura e mora geograficamente num mesmo território" (MUNANGA, 2003, p. 12).

Para Gomes, "[...] o racismo é, por um lado, um comportamento, uma ação resultante da aversão, por vezes, do ódio, em relação às pessoas que possuem um pertencimento racial observável por meio de sinais, tais como: cor da pele, tipo de cabelo, etc.”. A questão da discriminação é trazida por Souza (1997, p. 6), que vê o processo de discriminação como sexista e atribui-lhe concepções vistas como naturalizadas, envolvendo todo um contexto familiar, escolar, religioso, etc. No que se refere à noção de estereótipos, compartilhamos da reflexão de Silva (2003, p. 17), quando a autora pontua que "os estereótipos, ou seja, clichês, as imagens cristalizadas ou idealizadas de indivíduos ou de grupo de indivíduos" rotulam negativamente o sujeito, ou o grupo, produzindo o preconceito: a intolerância ao diferente.

Dadas as conceituações, seguimos com as reflexões sobre identidades sociais. Segundo Silva (2003), cabe ao professor ser um mediador entre aluno e material, tornando possível uma reflexão crítica, desenvolvendo um posicionamento próprio do aluno. A pesquisadora firma a importância do professor reflexivo e "[...] também de proporcionar uma ação corretiva e criadora sobre os estereótipos em relação ao negro no livro didático" (SILVA, 2003, p. 
20-21). Neste trabalho, refletimos sobre os materiais de ensino de Língua Inglesa (mas essas reflexões podem estender-se a todos os materiais utilizados, sendo eles de qualquer disciplina), posto que os professores da rede não utilizaram materiais distribuídos pelo MEC até o ano de 2010, e sim estavam elaborando ou fotocopiando seu próprio material didático. Entendemos que a pesquisa de Silva (2003) se relaciona com esta pesquisa à medida que traz as discussões sobre o racismo nos materiais utilizados pelos professores.

Pautado em uma perspectiva diacrônica, Silva (2005, p. 2) analisou discursos sobre negros e brancos nos livros didáticos de Língua Portuguesa para a $4^{\mathrm{a}}$ série do ensino fundamental no período correspondente ao ano de 1975 até o ano de 2004, falando sobre as ideologias presentes nos livros didáticos:

O estudo da ideologia é o estudo de como a circulação das formas simbólicas cria, institui, mantém e reproduz relações de dominação. Os discursos dos livros didáticos são tomados, portanto, sob o prisma da análise ideológica, ou seja, como forma de produção e difusão de discursos que fundam e sustentam relações de desigualdade, em nosso foco, racial.

Silva (2005, p. 2) ainda contribui com a discussão desse tema abordando o racismo à brasileira que está intrincado nas classes sociais, trazendo desvantagens para a população negra. Por intermédio de pesquisas como a de Silva (2005) entendemos que os livros didáticos e os materiais de ensino trazem os estereótipos, pois não incluem adequadamente a imagem do negro. Portanto, cabe a nós, professores, e não apenas às outras instituições sociais, pois podem não ter o mesmo esclarecimento crítico sobre esses temas, a continuidade da reflexão sobre o tema do racismo, bem como o incentivo a seu combate cada vez mais, tentando sua detecção, rompendo com os estereótipos para que as crianças sejam cidadãs mais conscientes do mundo multicultural e multiétnico em que vivem.

Ainda a respeito do racismo, Rosemberg, Bazilli e Silva (2003) ressaltam a dificuldade de mostrar para a sociedade a maneira sorrateira como o racismo se reproduz em ações cotidianas (ROSEMBERG, BAZILLI e SILVA, 2003, p. 127). Esses 
pesquisadores ainda refletem sobre a convivência "pacífica" entre o racismo contemporâneo, aquele que ilusoriamente não se percebe (ou é cômodo não perceber), mas que está presente nos fatos do cotidiano devido ao mascaramento da realidade e ao mito da democracia racial, ou seja, a crença, construída social e historicamente, de que os afrodescendentes não alcançam os mesmos patamares que os brancos, quer na área profissional, quer na educacional ou cultural, por falta de competência ou por falta de interesse, ignorando, assim, as desigualdades seculares que a estrutura social hierárquica cria, com prejuízos para os afrodescendentes (BRASIL, 2004).

Para explicar as dimensões estruturais, ideológicas e simbólicas do racismo, Rosemberg et al (2003, p. 128) retomam Essed (1991, p. 174):

Racismo é uma ideologia, uma estrutura e um processo pelo qual grupos específicos, com base em características biológicas e culturais verdadeiras ou atribuídas, são percebidos como uma raça ou grupo étnico inerentemente diferente e inferior. [...] na ideologia dominante, em geral não se reconhece que o racismo seja um problema estrutural. [...] o termo racismo é reservado apenas a crenças e ações que apoiam abertamente a ideia de hierarquias de base genética ou biológica entre grupos de pessoas. [...] $O$ discurso do racismo está se tornando cada vez mais impregnado de noções que atribuem deficiências culturais a minorias étnicas. Essa culturalização do racismo constitui a substituição do determinismo biológico pelo cultural.

As Diretrizes Curriculares Nacionais para a Educação das Relações Étnico-Raciais trazem a Lei Federal n. 10.639/2003, que alterou a Lei Federal n. 9.394, de 20 de dezembro de 1996, que estabeleceu as diretrizes e as bases da educação nacional, incluindo no currículo oficial da rede de ensino o tema História e Cultura AfroBrasileira em todas as disciplinas, instituindo, inclusive, o dia 20 de novembro como o dia da Consciência Negra. Com o advento da Lei Federal n. 10.639/2003, ficou evidente a preocupação com os cidadãos afrodescendentes. No Brasil, em várias universidades estaduais, federais e privadas, foram criados os Núcleos de Estudos Afro- 
Brasileiros (NEABs), que visam a promover atividades de pesquisa e extensão cujo tema são os estudos afro-brasileiros.

Apoiadas nas reflexões e nos dados apresentados, acreditamos que a mudança dos valores sociais e a diminuição das desigualdades poderão ser possível a partir do momento em que a escola "olhar" de maneira diferente para seus alunos, fazendo trabalhos contínuos voltados à reflexão sobre raça/etnia, entendendo e fazendo-os compreender seu valor como cidadãos brasileiros, negros ou não. Não estamos atribuindo, no entanto, o papel exclusivo de redentora à escola, nem toda a responsabilidade aos professores, pois a sociedade como um todo contribui para a formação dos cidadãos e para a construção das identidades sociais, mas acreditamos que a escola pode contribuir, e muito, com esse papel social, desconstruindo estereótipos permeados por ideologias vigentes por meio da materialização dos discursos pela linguagem. Então, a transformação social poderá partir da escola para a sociedade.

\subsection{Raça/etnia e as relações com os materiais de ensino}

Entendemos material de ensino (ou livro didático, material didático) como um material de apoio à aprendizagem, uma fonte importante de recursos para trabalhar a cultura e a identidade do aluno, não como única fonte de recursos, nem como verdade inquestionável para trabalhar apenas a língua pela língua, ou seja, com foco apenas no aprendizado de uma língua estrangeira, sem levar em conta a gama de informações que o aluno pode adquirir e conhecer pela língua e sobre esta mesma língua. É importante aperfeiçoá-lo, levar a funcionalidade didática aos alunos de modo que eles se tornem reflexivos ante o material que utilizam e tenham clareza da sua representação nele, e, no caso desta pesquisa, no que se refere à raça/etnia.

$\mathrm{O}$ trabalho com a diversidade étnico-racial nos materiais de ensino é fundamental para que as "diferenças" sejam minimizadas ou mesmo descaracterizadas do seu cunho pejorativo, socioculturalmente associado às diferentes raças/etnias. Certamente é um trabalho de longo prazo, mas é algo que precisa ser continuado para que possa ser bem-sucedido. 
Watthier (2008) trata da discriminação racial em livros didáticos e como ela pode influenciar na construção da identidade social dos alunos. A autora assevera que a discriminação racial afeta a vida dos alunos, cujas identidades sociais estão em processo de formação. Segundo a pesquisadora, seu trabalho teve o intuito de apresentar resultados, ainda que parciais, de uma pesquisa que versou sobre imagens e expressões sobre a temática racismo em livros didáticos, verificando qual é a representação do afrodescendente neles. Watthier traz para seu artigo contribuições de pesquisadores como Cavalleiro (2001), Silva (2002), Gomes (2005) e Ferreira (2006), o que lhe confere mais propriedade na reflexão sobre o racismo e a diversidade étnico-racial nos materiais didáticos.

Watthier (2008) também apresenta pesquisas que comprovam a veiculação estereotipada do afrodescendente pelo livro didático, trazido como pessoa inferior, prejudicando assim a construção identitária dos alunos (2008, p. 49, ver também FERREIRA; FERREIRA, 2011). Tal fator culminou na proibição da circulação de tais livros pelo PNDL. Cremos que este fato prejudica tanto alunos afrodescendentes quanto alunos de qualquer outra raça/etnia, ao passo que suas identidades podem ser negativamente construídas.

Acreditamos que este é o momento de clarear conceitos e minimizar diferenças, desmistificando-as. Como solução possível para esse problema, Watthier $(2008$, p. 51) traz a reflexão acerca do racismo e da discriminação. Associamos as ideias explanadas pela pesquisadora ao ensino baseado nas concepções do letramento crítico, pois, por meio de um ensino reflexivo, acreditamos que podemos mudar os pensamentos que parecem cristalizados tanto em brancos quanto em afrodescendentes.

O racismo e as outras formas de discriminação são desigualdades já naturalizadas pela sociedade como algo normal (HENRIQUES, 2002, p. 13). Talvez por isso, também no material de ensino os alunos e os professores não percebam o racismo ali contido. Sendo o discurso o lugar da reprodução (FIORIN, 2001, p. 32), essas desigualdades podem não estar apenas sendo naturalizadas, mas reproduzidas. Das formas de desigualdades existentes, Henriques (2002, p. 14) pontua que a racial é mascarada pelo silêncio, pois ela existe de forma velada na sociedade, impedindo a ascensão social da 
população negra.

A educação tem papel importantíssimo para reverter esse quadro, pois ela aparece "[...] como uma variável crucial para transformar significativamente a situação desigual em que se encontram os indivíduos de diferentes raças" (HENRIQUES, 2002, p. 15). O autor afirma que a pobreza no Brasil tem cor (HENRIQUES, 2002 , p. 29), é negra, e relaciona o fato de nascer negro com a fatalidade de permanecer pobre, isso devido às desigualdades sociais.

Focando também o gênero além da raça/etnia, Henriques (2002, p. 43) fala sobre as meninas negras no ensino fundamental e suas probabilidades sociais por meio de indicadores quantitativos, que são dados fornecidos por dados domiciliares de pesquisa do IBGE. O autor também realiza uma "[...] análise da distorção série-idade, que a partir do recorte racial nos mostra que, para todas as séries escolares e todos os anos da década, o indicador é significativamente pior para a população de cor negra". Tudo isso é indicado por meio de tabelas que demonstram essa oscilação na faixa de $20 \%$ e $25 \%$, o que não é pouco (HENRIQUES, 2002, p. 70).

Por sua vez, Oliveira (2009, p. 1) discute as práticas de leitura no que tange à questão raça e gênero com base na abordagem da análise crítica do discurso (ADC) e percebe, por intermédio de sua pesquisa, a presença de estereótipos de raça e gênero (neste trabalho limitar-nos-emos às reflexões sobre raça/etnia; as reflexões sobre gênero não serão aprofundadas aqui) nas atividades de leitura e pontua o quão importante é o papel do professor na desconstrução de tais conceitos.

É importante ressaltar que Oliveira (2009, p. 4) entende o termo "raça" como componente da identidade social, mas não no sentido biológico. Para tal entendimento, a pesquisadora reflete sobre as considerações de Borges (2002), D’Adesky (2002), Henriques (2002), Gomes (2007), entre outros. Ou seja, a cor da pele não é parâmetro para medir a inteligência nem a potencialidade do aluno, mas, sim, as oportunidades que lhe são dadas ou cerceadas durante sua vida escolar.

Assim, as diversas maneiras de utilizar os materiais didáticos, seja na leitura, seja na escrita ou em qualquer outra atividade, podem ser pensadas no sentido de tirar do silêncio os alunos não representados 
ali ou representados de uma maneira que os inferiorize, rotule e estigmatize. Essa situação pode gerar desperdício de talentos latentes ou promover rotulações para a vida social dos alunos.

\section{Encaminhamento metodológico}

O objetivo da pesquisa de campo foi entender como se deram as percepções das identidades sociais de raça/etnia por alunos acerca dos materiais de ensino utilizados por eles nas aulas de língua inglesa. O grupo pesquisado era composto de aprendizes de duas $8^{\mathrm{a}}$ séries $\left(9^{\circ}\right.$ ano do ensino fundamental) em duas escolas (Escola Amarela e Escola Azul $)^{1}$. Pretendeu-se com esta pesquisa também entender como os alunos se reconheciam ou aceitavam essas identidades.

A pesquisa foi de cunho qualitativo. A pesquisa qualitativa vem se firmando nas ciências sociais, nas ciências humanas e na psicologia. Os métodos qualitativos não são considerados independentes do processo da pesquisa, pois são compreendidos por meio dele. As novas situações decorrentes de uma mudança social acelerada e diversificada fazem com que pesquisadores cada vez mais se defrontem com novos contextos sociais: "[...] consequentemente, a pesquisa é, cada vez mais, obrigada a utilizar estratégias indutivas: em vez de partir de teorias para testá-las, são necessários 'conceitos sensibilizantes' para a abordagem de contextos sociais a serem estudados" (FLICK, 2004, p. 17-18).

Para esta pesquisa foram utilizados questionários e entrevistas. Os questionários tiveram caráter classificatório, pois a pesquisa se deu por amostragem. Foram escolhidos 12 alunos, sendo seis (três meninos e três meninas) de cada escola. Dentre esses tentamos selecionar alunos negros, brancos e pardos, para que fosse possível analisar em seus discursos as percepções de raça/etnia sobre si e sobre os colegas.

Vale ressaltar que nas entrevistas com os alunos primeiramente foram apresentados recortes de figuras (retiradas de jornais e revistas) durante o período em que o aluno estava sendo entrevistado. Esses recortes traziam representações de raça/etnia, de profissões, pessoas de

\footnotetext{
${ }^{1}$ Nomes fictícios.

124 Horizontes de Linguística Aplicada, ano 12, n. 1, 2013
} 
várias classes sociais, de gênero, ou seja, de diferentes identidades sociais. Pelo fato de os alunos não possuírem livro didático e sim materiais de ensino diversificados selecionados pelas professoras, as figuras pareceram ter facilitado a eles o processo de entendimento sobre essas representações identitárias, bem com puderam se tornar uma referência visual dos materiais de ensino que eles utilizam para suas aulas de língua inglesa desde o ano de 2009.

A coleta de dados ocorreu no ano de 2010. Durante a entrevista iniciou-se uma conversa sobre as identidades sociais que ali se encontravam representadas. Com as entrevistas gravadas e transcritas, iniciamos a análise dos dados, apresentada na seção denominada "Raça/etnia nas vozes dos alunos".

Esta pesquisa foi aprovada e acompanhada até sua conclusão pelo Comitê de Ética em Pesquisa com Seres Humanos (CEP) da Universidade Estadual do Oeste do Paraná (Unioeste). Como os dados coletados serão tornados públicos, optamos pelo uso de pseudônimos para preservar o anonimato das escolas e dos participantes da pesquisa.

Os alunos colaboradores da pesquisa tinham entre 12 e 17 anos, moravam em sua maioria em bairros próximos ou no mesmo bairro onde se encontravam as escolas, compartilhavam um contexto social semelhante e sempre estudaram em escola pública. Para que pudéssemos entender quais os materiais utilizados pelas professoras das turmas escolhidas, optamos por turmas nas quais as professoras já trabalhavam desde o ano de 2009. Considerando que a coleta de dados ocorreu em 2010, essa escolha possibilitou refletir sobre as percepções construídas desde o ano de 2009. Passamos agora às reflexões sobre os excertos dos alunos entrevistados.

\section{Raça/etnia nas vozes dos alunos entrevistados}

A presença predominantemente de pessoas brancas nos livros didáticos já foi constatada por alguns estudiosos da área, como Silva (2003), Henriques (2002) e Silva (2008). Este último constatou 16,2 personagens brancas para cada personagem negra. Trata-se de pesquisa recente, que se torna relevante na medida em que podemos pensar esses dados como existentes em outros materiais, como, por exemplo, 
nos materiais de língua inglesa. Com o desenvolvimento da pesquisa pudemos perceber que essa predominância se aplica não só ao LD, mas também aos materiais compilados pelos professores, que, por várias razões, nem sempre observam as representações de raça/etnia que poderiam ou deveriam estar presentes nas atividades levadas para a sala de aula.

Os alunos acreditam que as pessoas negras não aparecem em seu material ou aparecem pouco, mas eles não falam apenas de seus materiais, falam do que aprenderam, do que conhecem, dos preconceitos adquiridos e cristalizados pelo tempo:

"Quase nunca apareceu, mas, quando aparece, sempre é os brancos por cima e os negros lá por baixo" (aluna Laura, Escola Amarela, 07/06/2010).

“[...] tem uns piá na minha sala que são brancos, sabe, mas não branco, branco, porque nem todo mundo é branco, né. Aí um piá falou para o Antônio, sabe aquele piá moreninho ali da sala? E chamoo ele de moreninho... de... negro. Daí ele ficou bravo, né. Daí ele falou: Ah, que tem eu ser negro, né” (aluna Patrícia, Escola Azul, 17/06/2010).

Alguns dos adolescentes entrevistados pareciam ter vergonha de utilizar a palavra "negro". A aluna Patrícia, quando questionada pela pesquisadora sobre o motivo de não querer falar, afirmou: "Ah, prof., é falta de educação, eu acho" (nota de diário de campo, Patrícia, Escola Azul, 17/06/2010). Ela se referia aos amigos como "aquele moreninho escuro, aquele mais moreno do que eu," mas acreditava ser falta de educação dizer a palavra negro. Azevedo (2009, p. 25), em sua dissertação de mestrado, refletiu sobre questões de raça/etnia, bem como sobre suas próprias experiências como mulher negra. Ela conta que, quando criança, dizia que seu irmão era "mais negro" do que ela, usava das mesmas estratégias numa tentativa de negar suas raízes "africanas".

É importante tomar conhecimento da complexidade que envolve o processo de construção da identidade negra em nosso país. Processo esse marcado por uma sociedade que, para discriminar os negros, utiliza-se tanto da

126 Horizontes de Linguística Aplicada, ano 12, n. 1, 2013 
desvalorização da cultura de matriz africana como dos aspectos físicos herdados pelos descendentes de africanos. Nesse processo complexo é possível, no Brasil, que algumas pessoas de tez clara e traços físicos europeus, em virtude de o pai ou a mãe ser negro(a), se designem negros; que outros, com traços físicos africanos, se digam brancos. É preciso lembrar que o termo negro começou a ser usado pelos senhores para designar pejorativamente os escravizados, e este sentido negativo da palavra se estende até hoje. Contudo, o Movimento Negro ressignificou esse termo dando-lhe um sentido político e positivo (BRASIL, 2005, p. 15-16).

A citação anterior somente enfatiza a complexidade de discussão no Brasil acerca das relações étnico-raciais.

“[...] um dia eu tava andando na rua, sabe, dai o piá me chamou de gordinha, porque sou gordinha, né. E ele era moreno, eu cheguei assim e olhei pra cara dele e falei: cala a boca seu negro encardido, daí eu saí andando e cheguei em casa, falei pra minha mãe, né. A mãe falou: não... isso é errado. Não é só porque a pessoa te chamou de gordinha que você tem que chamar ela de negra, né" (aluna Patrícia, Escola Azul, 17/06/2010).

Patrícia admite que teve uma atitude racista. Sua mãe, no intuito de ajudar a filha a refletir sobre o assunto, parece conseguir apenas naturalizar a aparente inferiorização do negro, quando diz: "chamar ela de negra", ou seja, associando talvez a palavra negro a um sentido pejorativo, neste caso, de xingamento mesmo. Talvez fosse preciso que a mãe da menina refletisse com ela sobre o erro do garoto em chamá-la de gordinha, da mesma forma que ela estava errada em chamá-lo de negro, pois estava, ao chamá-lo de negro, enfatizando que ser negro está associado à sujeira. É comum encontrar pesquisas que apontam que xingamentos como esse são comuns (GUIMARÃES, 2000) quando se quer inferiorizar o negro.

A atribuição de inferioridade consiste em justaposição de uma marca com a cor, como também relação de qualidades ou propriedades negativas e com relação à constituição Horizontes de Linguística Aplicada, ano 12, n. 1, 2013 
física, moral, organização social, hábitos de higiene, $e$ humanidade, para certo grupo de pessoas consideradas "negras" ou "pretas". (GUIMARÃES, 2003, p. 148 apud FERREIRA, 2009, p. 3).

Durante a entrevista do aluno Luiz Carlos houve referência direta à noção de estereótipos. Em um determinado momento o aluno pede para que se trabalhe mais as loiras nos materiais e aponta a foto. A pesquisadora então o questiona sobre a foto da modelo negra que está sobre a mesa ao lado da foto da modelo loira e ele responde:

“Ah, não é ser racista mas... mas não faz meu tipo, né. Ela parece brilhante, né. Parece que brilha. Eu não sou racista, meu pai é quase da cor dela. Meu pai é preto mas só que tem o cabelo liso" (Luiz Carlos, Escola Azul, 22/06/2010).

A respeito do cabelo, Gomes diz que "[...] ele é um dos elementos mais visíveis e destacados do corpo. Em todo e qualquer grupo étnico ele é trabalhado e manipulado, todavia a sua simbologia difere de cultura para cultura. Esse caráter universal e particular do cabelo atesta a sua importância como símbolo identitário" (GOMES, 2003, p. 174) - identidade essa que não se assume pelo fato de o cabelo não ser crespo, assim, a tentativa de negação da raça traz algumas questões que seriam consideradas características biológicas, não refletindo a questão como uma construção social, o que pode ser observado por exemplo na afirmação: "Meu pai é preto, mas só que tem o cabelo liso" e "e do olho verde ainda" (Luiz Carlos, Escola Azul, 22/06/2010). Para entender essa questão vale trazer a explicação de raça e cor:

O tema raça é ainda mais complexo na medida em que inexistem no país regras fixas ou modelos de descendência biológica aceitos de forma consensual. Afinal, estabelecer uma "linha de cor" no Brasil é ato temerário, já que essa é capaz de variar de acordo com a condição social do indivíduo, o local e mesmo a situação. Aqui, não só o dinheiro e certas posições de prestígio embranquecem, assim como, para muitos, "a raça", transvestida no 
conceito cor, transforma-se em condição passageira $e$ relativa" (SCHWARCZ, 1998, p. 182).

Concordando com a definição anterior no sentido da complexidade a que nos remete o termo raça e também seguindo os estudos de Ferreira (2009, p. 2), entendemos que a atitude de Luiz Carlos pode estar remetendo ao "processo de embranquecimento" que ocorre no Brasil, sendo uma estratégia utilizada para criar uma aproximação da cor branca, descaracterizando a ascendência negra, negando, assim, a possível origem: "Ele é que nem o João, mas tem olho verde" (Luiz Carlos, Escola Azul, 22/06/2010).

Luiz Carlos insiste nas características olho verde e cabelo liso, certamente para tentar descaracterizar seu pai como negro, e aponta o colega, a quem, implicitamente, também acaba por chamar de negro. Não podemos esquecer também de que ter cabelo liso e olho claro traz status social. Por seu pai ser negro e sua mãe branca, ele se reconhece como pardo.

“ [...] então essa parte do preconceito tem lá na sala o... Romeu, que quase todo mundo fica falando besteira, que muita gente ri né, eu percebo. Ficam assim, dando apelidinho meio sem graça pra ele, dá pra perceber que ele não gosta, mas só que tem gente sabe né que, não tá nem ai"” (Rosa, Escola Amarela, 14/06/2010).

"[...] estavam falando sobre jogar bola daí, diz que o seu fulano lá, não sei..., o que ia fazer o gol e não fez, daí o outro gritou lá: Ai, tinha que ser nego mesmo" (Ana, Escola Azul, 17/06/2010).

Ana reflete sobre o que aparece em seu material de ensino, entende que as pessoas brancas normalmente aparecem mais vezes em uma situação de maior prestígio econômico e relata uma situação de preconceito que presenciou na escola, na aula de educação física.

"Os pretos... tipo assim... negros [...], sempre como pobres e os brancos tipo ricos" (João, Escola Azul, 22/06/2010). 
"Me chamaram de preto e de indígena" (João, Escola Azul, 22/06/2010).

João, que diz se reconhecer como pardo, afirma, em outro momento da entrevista, que as brincadeirinhas de cunho racista acontecem, mas ele não presta atenção. Ou seja, ela usa a estratégia de silenciamento, não reclama. Ele admite que não gosta de ser chamado de preto e de indígena, mas não fala muito sobre o assunto, pois parece não querer pertencer ao grupo étnico negro e, ao mesmo tempo, parece silenciado por alguma situação que faz com que seus amigos façam brincadeiras com relação a sua cor. Ele também parece ter internalizado a palavra negro como pejorativa, talvez por esse motivo tenha ficado encabulado quando se referiu aos afrodescendentes como pretos e negros.

A respeito do silenciamento, Ferreira diz que "dentro das salas de aula, é necessário questionar a prática do discurso que silencia as vozes dos alunos. Se os processos das salas de aula são construídos através do discurso, eles podem ser construídos através da linguagem" (FERREIRA, 2006, p. 49). Ainda no momento da entrevista de João, Luiz Carlos resmunga no cantinho da sala que seu colega João "é pretinho", no momento em que este se declara de cor parda. João fica sem graça e diz: "Cala a boca, racista, vou te processar [...] (em tom de brincadeira)" (Nota do diário de campo, Escola Azul, 17/06/2010).

"[...] teve uma vez que a professora de geografia, ela passou um vídeo que mostrava um piazinho morrendo e o urubu atrás, assim sabe, esperando ele morrer para comer ele" (Patrícia, Escola Azul, 17/06/2010).

Segundo os alunos, as discussões sobre raça/etnia não parecem ser aprofundadas, no sentido de esclarecer os valores que cada grupo tem, são discursos que aparecem em sala para confirmar a visão global que se tem dos grupos inferiorizados. A fala anterior demonstra a visão que os alunos tiveram sobre essa referida aula, com a associação da África apenas com miséria e morte. Esse vídeo parece ter feito os alunos refletirem sobre a pobreza, mas mostrou apenas um lado negativo, sem mais explicações. Isso fica evidenciado pela fala de outros alunos: Luiz Carlos e Giovani, ao final da entrevista, 
continuaram falando do tal vídeo do urubu, juntamente com outras colegas de classe (Notas do diário de campo, 22/06/2010).

"Porque eles trazem pessoas brancas. Eu não consigo me ver" (Romeu, Escola Amarela, 14/06/2010).

"Aparecer mais negros e classe social mais pobre. Menos favorecidas" (Romeu, Escola Amarela, 14/06/2010).

Romeu (o único aluno que se declara negro na sala), bem como a maioria de seus colegas, acredita não estar representado nos materiais que utiliza: O caso de Romeu pode estar sendo reflexo de uma situação comum no Brasil, que se chama racismo institucional, e que "[...] consiste no fracasso coletivo de uma organização de fornecer um serviço apropriado e profissional para as pessoas por causa de sua cor, cultura, ou origem étnica" (MACPHERSON, 1999, p. 321 apud FERREIRA, 2009, p. 78).

\section{Considerações finais}

O tema raça/etnia, em muitos casos, acaba por se tornar um folclore trabalhado uma vez por ano em um evento que envolva todos os alunos, mas, no cotidiano, nem sempre é introduzido nas várias oportunidades que poderiam ser criadas para a reflexão em sala, contribuindo para a reflexão sobre os estereótipos e culminando em sua desconstrução (SILVA, 2001, p. 45; REIS, 2008). O trabalho no cotidiano serve para que os alunos possam compreender que existem diversos discursos que agem e reproduzem o poder na sociedade (HAWKINS; NORTON, 2009, p. 33), interpretando-os, tornando possível assim desfazer rotulações de dominação nos materiais e também na sociedade.

Fica evidente que, muitas vezes, os alunos que participaram desta pesquisa percebem que seria melhor existir um trabalho mais voltado à raça/etnia em sala de aula, bem como muitas vezes não conseguem compreender que as brincadeiras e os xingamentos proferidos em sala de aula e fora dela fazem parte de uma educação que veio, normalmente, do próprio núcleo familiar, entre outros

Horizontes de Linguística Aplicada, ano 12, n. 1, 2013 
contextos, e como essas questões são geralmente naturalizadas, tornase difícil sua visualização nos contextos em que ocorrem, mesmo que intuitivamente eles saibam que ser negro no Brasil, mais do que as características físicas observáveis, é uma questão política (BRASIL 2004, p. 15).

Em linhas gerais, os alunos não se sentem representados no material didático que utilizam. Eles acreditam que a realidade é distante da deles em relação às identidades sociais de raça/etnia, classe, etc. Em relação à raça/etnia, os alunos pardos e negros acreditam que seus grupos não aparecem, ou não aparecem com frequência, nos materiais que utilizam.

Nesses poucos trechos das entrevistas realizadas sobre 0 material de ensino, os alunos colocam em seus discursos representações sobre raça/etnia que transpõem os limites do material escolar de língua inglesa utilizados por eles, trazem suas vivências e experiências cotidianas que influenciam o modo de pensar e ver o mundo. A intenção desta reflexão foi contribuir para a disseminação das discussões sobre raça/etnia para empoderar os alunos para que sejam capazes de refletir criticamente sobre a diversidade brasileira para que, ao se construir ou se propagar conceitos, onde quer que seja (na escola, na família, no trabalho, entre outros), se tenha a consciência de fazê-lo de modo que não se inferiorize nem estereotipe nenhuma classe, raça, etnia ou gênero. Segundo Souza (2005) é necessária a reflexão contínua sobre essas questões para que seja possível mudar os conceitos pejorativos naturalizados para o termo "negro", e isso será possível com a continuidade de pesquisas, de militantes da questão racial, devolvendo a autoestima e a cidadania ao povo negro do Brasil.

\section{Referências}

AZEVEDO, Aline S. Reconstruindo identidades discursivas de raça na sala de aula de língua estrangeira. 2009. 185 p. Dissertação (Mestrado em Linguística Aplicada) - Faculdade de Letras, Universidade Federal do Rio de Janeiro, Rio de Janeiro, 2009.

BRASIL. Lei n. 10.639, de 9 de janeiro de 2003. Ensino sobre história e cultura afro-brasileira. Brasília: Ministério da Educação, 2003.

132 Horizontes de Linguística Aplicada, ano 12, n. 1, 2013 
- Parecer n. CNE/CP3/2004. Diretrizes curriculares nacionais para a Educação das relações étnico-raciais e para o ensino de história e cultura afro-brasileira e africana. Brasília: Ministério da Educação; Conselho Nacional de Educação. 17 p. 2004.

- Diretrizes curriculares nacionais para a Educação das relações étnico-raciais e para o ensino de história e cultura afrobrasileira e africana. Brasília: Ministério da Educação, 2005.

FABRÍCIO, Branca F.; MOITA LOPES, Luiz P.. Discurso e vertigens: identidades em xeque em narrativas contemporâneas. Veredas. Rev. Est. Ling., Juiz de Fora, v. 6, n. 2, p. 11-29, 2002.

FERREIRA, Aparecida J. Formação de professores de línguas: investigações e intervenções. Cascavel: Edunioeste, 2009.

- Formação de professores raça/etnia: reflexões e sugestões de materiais de ensino. Cascavel: Coluna do Saber, 2006.

FERREIRA, Aparecida J.; FERREIRA, Susana A.. Raça/etnia, gênero e suas implicações na construção das identidades sociais em sala de aula de línguas. RevLet: Revista Virtual de Letras, v. 3, n. 2, p. 114129, ago./dez., 2011.

FIORIN, José L. Linguagem e ideologia. São Paulo: Ática, 2001.

FLICK, Uwe. Uma introdução à pesquisa qualitativa. Tradução: Sandra Netz. Porto Alegre: Bookman, 2004.

GOMES, Nilma L. Educação, identidade negra e formação de professores/as: um olhar sobre o corpo negro e o cabelo crespo. Educação e Pesquisa, v. 29, n. 1, p. 167-182, 2003.

Alguns termos e conceitos presentes no debate sobre relações raciais no Brasil: uma breve discussão. In: BRASIL. Educação antirracista: caminhos abertos pela Lei Federal n. 10.639/2003. Brasília: Ministério da Educação; Secretaria de Educação Continuada, Alfabetização e Diversidade, 2005 
GUIMARÃES, Antonio S. A. O insulto racial: as ofensas verbais registradas em queixas de discriminação. Estudos Afro-Asiáticos, n.38, p. 31-48, 2000.

HALL, Stuart. A identidade cultural na pós-modernidade. 11 ed. Rio de Janeiro: DP\&A, 2006.

HAWKINS, Margaret R.; NORTON, Bonny. Critical language teacher education. In: BURNS, Anne; RICHARDS, Jack (Eds.). Cambridge guide to second language teacher education. Cambridge: Cambridge University Press, 2009. p. 30-39.

HENRIQUES, Ricardo. Raça e gênero no sistema de ensino: os limites das políticas universalistas na educação. Brasília: Unesco 2002.

MOITA LOPES, Luiz P. Identidades fragmentadas: a construção discursiva de raça, gênero e sexualidade em sala de aula. Campinas: Mercado de Letras, 2002.

MUNANGA, Kabengele. Uma abordagem conceitual das noções de raça, racismo, identidade e etnia. Palestra proferida no $3^{\circ}$ Seminário Nacional de Relações Raciais e Educação - PENESB-RJ, em 5 nov. 2003.

OLIVEIRA, Elania de. Práticas de leitura em aulas de português e o tratamento das questões raciais e de In: CONGRESSO DE LEITURA DO BRASIL (COLE), 17, 2009, Campinas. Anais... Campinas: Instituto Pró Livro, 2009. p.512

REIS, Rosani C. C. Diversidade étnico-racial: a Lei Federal n. 10.639/2003 e abordagens possíveis em sua aplicação. 2008. 201 p. Dissertação (Mestrado em Letras) - Centro de Educação, Comunicação e Artes, Universidade Estadual do Oeste do Paraná, Cascavel, 2008.

ROSEMBERG, Fúlvia; BAZILLI, Chirley; SILVA, Paulo V. B. Racismo nos livros didáticos brasileiros e seu combate: uma revisão da literatura. Educação e Pesquisa, v. 29, n. 1, p.125-146, 2003. 
SANTOS, Veralice A. M. Constituição identitária do ser professor em um contexto étnico-racial. Dissertação (Mestrado em Letras) - Centro de Educação, Comunicação e Artes, Universidade Estadual do Oeste do Paraná, Cascavel, 2007.

SILVA, Ana C. Desconstruindo a discriminação do negro no livro didático. Salvador: EDUFBA, 2001.

SILVA, Paulo V. B. Relações raciais em livros didáticos de língua portuguesa. Tese (Doutorado em Psicologia) - Faculdade de Ciências Humanas e da Saúde, Pontifícia Universidade Católica de São Paulo, São Paulo, 2005.

- Racismo em livros didáticos, estudo sobre negros e brancos em livros de língua portuguesa. Belo Horizonte: Autêntica Editora, 2008 (Coleção Cultura negra e identidades).

SOUZA, Francisca M. N. Linguagens escolares e reprodução do preconceito. In: Educação anti-racista: caminhos abertos pela Lei Federal 10639/2003. Secretaria da Educação Continuada, Alfabetização e Diversidade. - Brasília: Ministério da Educação, Secretaria de Educação Continuada, Alfabetização e Diversidade, 2005.

SOUZA, Fabiana C. A prática pedagógica na escola: reprodução de estereótipos sexuais. p. 23-45, São Paulo, 1997. In: $23^{\mathrm{a}}$ Reunião Anual da ANPEd. Disponível em: <http://23reuniao.anped.org.br/textos/0712p.pdf>. Acesso em: 11 jun. 2014.

SCHWARCZ, Lilia M. Nem preto nem branco, muito pelo contrário: cor e raça na intimidade. In SCHWARCZ, Lília M. História da vida privada no Brasil: contrastes da intimidade contemporânea. São Paulo: Companhia das Letras, 1998.

WATTHIER, Luciane. A discriminação racial presente em livros didáticos e sua influência na formação da identidade dos alunos. Revista Urutágua, n. 16, 2008. 
Vozes de aprendizes acerca de identidades sociais

Submetido em: 13/03/13

Aceito em: 12/05/14

Title: Learners' voices about race/ethnicity at school: perceptions about didactic materials

136 Horizontes de Linguística Aplicada, ano 12, n. 1, 2013 